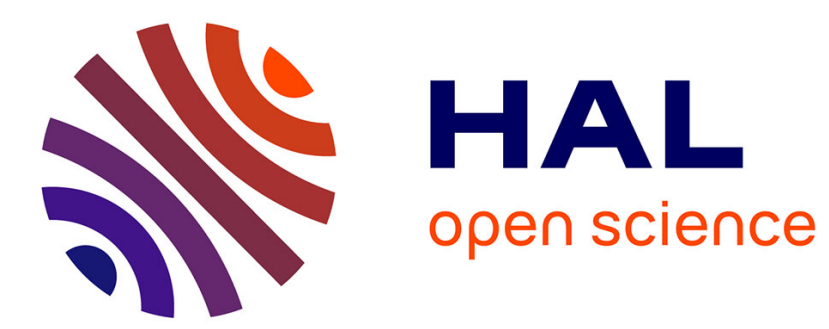

\title{
Book reviews, Fall 2012
}

Pierre Alquier, Christian Robert

\section{- To cite this version:}

Pierre Alquier, Christian Robert. Book reviews, Fall 2012. CHANCE, 2012, 25 (4), pp.57-61. 10.1080/09332480.2012.752298 . hal-00725645

\section{HAL Id: hal-00725645 \\ https://hal.science/hal-00725645}

Submitted on 27 Aug 2012

HAL is a multi-disciplinary open access archive for the deposit and dissemination of scientific research documents, whether they are published or not. The documents may come from teaching and research institutions in France or abroad, or from public or private research centers.
L'archive ouverte pluridisciplinaire HAL, est destinée au dépôt et à la diffusion de documents scientifiques de niveau recherche, publiés ou non, émanant des établissements d'enseignement et de recherche français ou étrangers, des laboratoires publics ou privés. 


\title{
Book reviews, Fall 2012
}

\author{
Pierre Alquier ${ }^{1,2}$ and Christian P. Robert ${ }^{2,3,4}$ \\ ${ }^{1}$ Université Denis Diderot, ${ }^{2}$ CREST, ${ }^{3}$ Université Paris-Dauphine, CEREMADE, and ${ }^{4}$ IUF \\ alquier@ensae.fr, xian@ceremade.dauphine.fr
}

August 27, 2012

\begin{abstract}
This note is made of a review of the books by Bryson (2011), Diaconis and Graham (2011), Havil (2012), and Langville and Meyer (2012), respectively. They are scheduled to appear in the next issue (25(4)) of CHANCE.
\end{abstract}

The second review of Havil (2012) is written by Pierre Alquier ${ }^{1}$, while the three other reviews are written by Christian P. Robert.

\section{Magical Mathematics by Persi Diaconis and Ron Graham}

- Hardcover: 258 pages

- Publisher: Princeton University Press

- Year: 2011

- Language: English

- ISBN-13: 978-0-6911-5164-9

'The two of us have been mixing entertainment with mathematics for most of our lives.' P. Diaconis and R. Graham (page xi).

\footnotetext{
${ }^{1}$ Pierre Alquier is a "maître de conférences" at Université Paris 7 and a research fellow at CREST. He holds a $\mathrm{PhD}$ from Université Paris 6. His research themes are high dimensional estimation and aggregation of estimators in statistics.
} 
When I learned that Persi Diaconis and Ron Graham had co-authored a book on the mathematics of magic, the Book Editor of CHANCE immediately asked Princeton University Press for a copy! Even though I am not at all interested in card tricks. Nor in juggling. (The title is a wee confusing to me as it sounds as focussing on the magics of mathematics rather than the converse. The subtitle sheds some light on this confusion: The Mathematical Ideas that Animate Great Magic Tricks.)

Once the book had arrived, I showed the book to my wife and she started reading it right away, going over the first chapter prior to giving it back to me. Later, on a plane trip between Phoenix and Minneapolis, I happened to sit next to a professional magician, The Amazing Hondo!, who started chatting with me and telling me about his work and some of his tricks. He knew about Persi as a magician but was surprised he was equally famous among mathematicians. Hondo showed me a few (impressive) sleights of hand and explained a nice mathematical trick (based on creating apparent randomness while always extracting the same number of cards from the pile). As I happened to have the book with me, he took a look at it, commenting on one trick, and wrote down the reference. Overall, I have had a few other occurrences of how the book attracted the attention of non-magicians and/or non-mathematicians: this illustrates the appeal of the concept of this book for a very wide audience and, of course, once one starts reading the book, the attaction is increased manyfold. It is indeed a very entertaining book, with a fairly easy mathematical level, and it is also a beautiful product, with wide margins, fancy (but readable) fonts, photographs, and graphs or tables in the margins.

'Both of our worlds have a dense social structure: thousands of players turning ideas over and over.' P. Diaconis and R. Graham (page xi)

The entertaining and cosy style of Mathematical Magics (oops, Magical Mathematics!) does not mean it is an easy read. First, conceptualising the card manipulations requires a good analytic mind if one does not have a deck of cards available. Second, the connections with mathematics involve several subfields and not only combinatorics. Like de Bruijn sequences and graphs, the Mandelbrot set, Penrose tiling. And even Bayesian analysis for reversible Markov chains (p.42) and the I Ching. The last chapters are however less directly related to maths (even though Chapter 10 about great mathematical magicians includes connections with topology).

Interestingly (for us academics), the book mentions a (Banff) BIRS 2004 workshop relating to magics via de Bruijn sequences and Gray codes. With 
the traditional conference picture in front of the (old) BIRS building. (Another item of information, IBM stands for International Brotherhood of Magicians!)

'We hope that our book will shine a friendly light on the corners of the world that are our homes.' P. Diaconis and R. Graham (page xii)

One of the complaints I share with my wife about Magical Mathematics is that some of the tricks are not explained in full enough detail. At least for some non-native speakers like us. For instance, during the Christmmas break, my nephew and I tried the Gilbreath principle and could not make it work without forcing the perfect riffle-shuffle one card at a time. The sentence "the shuffle doesn't have to be carefully done" (p.63) set us on the wrong track. On pages 106 and 107, the titles of two 1500's books in French are quoted with one typo (sont versus font, but at the time $s$ and $f$ were typed quite similarly) and a missing $s$ in Inventions.

Overall, this is a wonderful book, potentialy enjoyable by a large range of individuals. The order behind the apparent randomness of card tricks became clearer and clearer to the naïve reader I am as I was reading on. And the warmth and communal spirit of the magician community transpires through the last chapters. (Note there is a $\$ 1000$ reward posted within the book!)

\section{The irrationals: A story of the numbers you can't count on, by Julian Havil}

- Hardcover: 320 pages

- Publisher: Princeton University Press (July 22, 2012)

- Language: English

- ISBN-10: 0691143420

This book is intended to be a short history of irrational numbers, since the discovery of the first irrational, $\sqrt{2}$, by the ancient Greeks until the first rigorous definitions of real numbers by Cantor and Dedekind. In addition to the historical aspect, the author does not hesitate to go into mathematical details and to provide some of the most remarkable proofs in the history of irrationals. 
The book is essentially organized around the emergence of key mathematical concepts, rather than based on a strict chronological order. Thanks to the historical perspective, we learn a lot about some famous mathematicians like Pythagoras, Euclid, Gauss or Euler. The book is also full of amazing anecdotes. For example, it reveals the way to find the tomb of Roger Apéry, who proved that $\zeta(3)$ is irrational, in the labyrinth of "Père Lachaise" cimetery in Paris. All of this make the reading of this book a real enjoyment. The appendix contains more involved mathematical developments. The only weak point that I would like to point out is the absence of bibliography that would allow the interested reader to go further into the history of number theory, or into number theory itself.

The book can roughly be divided into 4 parts: (1) the discovery of irrationals and the first calculus with square roots, in chapters 1 and 2 , (2) the proof that some remarkable numbers like $\pi$ and $e$ are irrationals in chapters 3, 4 and 5, (3) some classification of the irrationals based on approximations by rationals, and the discovery of transcendental numbers (Chapters 6, 7 and 8) and, finally, (4) the proper definition of the real numbers by several mathematicians, including Dedekind (9 and 10).

Chapters 1 and 2 deal with the antique world: the proof of the irrationality of $\sqrt{2}$, the influence of the Pythagoras and Euclid, and the first algebraic manipulations of the irrationals by the Arabs, the Hindus and European mathematicians like Fibonacci in the early Renaissance. A lot of information is provided about several Greeks mathematicians and philosophers and the reader might sometimes get lost. However, both chapters contain valuable historical information, as well as some nice proofs based on geometry.

Chapters 3, 4 and 5 give the proof of the irrationality of some remarkable numbers. The method of continued fractions is explained in Chapter 3, leading to the irrationality of $e$. A simpler proof due to Fourier is given in Chapter 4. The proof of the irrationality of $\pi^{2}$ (and thus of $\pi$ ) by Hermite is also given in details in that Chapter. Chapter 5 takes the reader to the seventies: it provides the striking proof of that $\zeta(3)$ is irrational by Roger Apéry. Surprisingly enough, unlike most recent mathematical proofs, this one only requires a knowledge of elementary mathematics to be understood.

Chapter 6 is one of the most remarkable parts of the book, because of the number of results given there, and the elegance of the proofs. It focuses on approximations of irrationals by rationals. It is obvious that, given any number $x$ and an integer $q$, one can find another integer $p$ with $|x-p / q|<1 / q$. However, is it possible to find infinitely many $p$ and $q$ such that $|x-p / q|<1 / q^{1+\varepsilon}$ for a given $\varepsilon>0$ ? One of the striking facts 
proved in this chapter is that for $\varepsilon=1$, the answer is yes if, and only if, $x$ is irrational. In Chapter 7, a classification of irrationals based on various values for $\varepsilon$ is described. The idea is to define a number $x$ to be "more irrational" if the property still holds for larger values of $\varepsilon$. This leads to the introduction of a new family of irrationals: the transcendentals, studied in Chapters 7 and 8. Actually, if the property holds for $\varepsilon>1$, then $x$ is a transcendental number. It's been conjectured for a long time that $\pi$ and $e$ are transcendentals. However, the first number $L$ to be proved to be transcendental was specially designed by Liouville to fit the results of Chapter 6. This construction is explained in Chapter 7: $L$ is build such that, for any $\varepsilon>0$, there are infinitely many $p$ and $q$ such that $|L-p / q|<1 / q^{1+\varepsilon}$, and this proves that $L$ is transcendental.

Finally, Chapter 9, 10 and 11 deal with more recent questions such as the problem of randomness in the decimal expansion of irrational numbers, and the first rigourous definitions of the set $\mathbb{R}$ of real numbers by Kossak, Cantor, Heine and Dedekind. Dedekind's definition of a real number as a cut of the set of rationals became the classical one, but it is known that the other constructions are equivalent. The chapter about randomness is a bit short and unfortunately the recent approaches to define random sequences by Chaitin, Solovay and Martin-Löf are not mentionned. This part ends with some conclusion on the role of irrationals in modern mathematics.

This book contains a lot of fun for whoever likes mathematics. As it goes into details, I would recommend it particularly to students or to mathematicians non specialized in number theory, who would like to learn about its history - or just to enjoy some remarkably elegant proofs. From that perspective, some chapters like Chapers 6 and 10 are particularly successful.

\section{Seeing Further: The Story of Science, Discovery, and the Genius of the Royal Society, edited by Bill Bryson}

- Paperback: 512 pages

- Publisher: William Morrow Paperbacks; Reprint edition (November 8, 2011)

- Language: English

- ISBN-10: 0061999776 
'I can tell you at once that my favourite fellow of the Royal Society was the Reverend Thomas Bayes, from Turnbridge Wells in Kent, who lived from about 1701 to 1761. He was by all accounts a hopeless preacher, but a brilliant mathematician.' Bill Bryson, page 2.

After becoming aware of this book thanks to a Bayesian tweet (!), I eventually managed to get hold of Bill Brysons "Seeing Further: The Story of Science, Discovery, and the Genius of the Royal Society". Now, a word of warning: Bill Bryson is the editor of the book, meaning he wrote the very first chapter, plus a paragraph of introduction to the 21 next chapters. If, like me, you are a fan of Brysons hilarious style and stories (and have been for the past twenty years, starting with "Mother Tongue" about the English language), you will find this distinction rather unfortunate, especially because it is not particularly visible... But, after opening the book, you should not remain cross very long, and this for two reasons: the first one is that Bayess theorem appears on the very first page (written by Bryson, mind you!), with enough greek letters to make sure we are talking of our Bayes rule! This reason is completed by the above sentence which is in fact the very first sentence in the book! Bryson took for sure a strong liking to Reverent Bayes to pick him as the epitome of a FRS! And he further avoids using this suspicious picture of the Reverent that plagues so many of our websites and slides... Bryson includes instead a letter from Thomas Bayes dated 1763, which must mean it was sent by Richard Price towards the publication of "An Essay towards solving a Problem in the Doctrine of Chances" in the Philosophical Transactions, as Bayes had been dead by two years at that time.

What about my second reason?! Well, the authors selected by Bryson to write this eulogy of the Royal Society are mostly scientific writers like Richard Dawkins and James Gleick, scientists like Martin Rees and many others, and even a cyberpunk writer like Neal Stephenson (whom Anathem I reviewd in this column a few issues ago), a selection that should not come as a surprise given his monumental Baroque Cycle, a trilogy about Isaac Newton and friends. Now, Neal Stephenson gets to the next level of awesome by writing a chapter on the philosophical concepts of Leibniz, FRS, the monads, and the fact that it was not making sense until quantum mechanics was introduced (drawing inspiration from a recent book by Christia Mercer). Now, the chapters of the book are quite uneven, some are about points not much related to the Royal Society, or bringing little light upon it. But overall the feeling that perspires throughoutthe book is one of tremendous achievement by this conglomerate of men (and then women starting in 1945!) 
who joined a Society about useful knowledge in $1660 \ldots$

I quite liked Gleicks depiction (Chapter 1) of the early experiments ran by the Society, showing a curiosity about everything (meaning really everything, including the most ridiculous superstitions!), disliked Atwoods essay (Chapter 2) on the figure of the "mad scientist" and Maggie Gees text (Chapter 18) on the "end of the world" as they were very much unrelated to the Society, as well as Wertheims study (Chapter 3) of the impact of Newtonian physics on cosmology and faith (maybe because quoting Star Treck and X-Files does not seem to belong there!, maybe because of the cheap philosophy underlying the text). More interestingly, Paul Davies rekindles the debate in Chapter 14 about the not-such-a-special-place features of our location (i.e., Earth).

I have already mentioned Neal Stephensons superb foray into Leibniz metaphysics (Chapter 4), definitely worth reading and reminding me in the last part of the great Logicomix book. Rebecca Goldsteins (Chapter 5) on the apparent opposition between mathematical and empirical approaches within the Society is quite fascinating, concluding on Wigners "unreasonable effectiveness of mathematics" (and making me realise that Francis Bacon was almost contemporary to the creation of the Society). Philip Ball comes back to Bacon in Chapter 13, with his call for an experimental philosophy oriented towards applications. Simon Schafer's Chapter 6 is about an epiphenomenon, namely the dispute within the Society as whether or not spiked rods were effective against lightning strikes, followed by another mildly interesting chapter by Richard Holmes on ballooning and the reserve of the Society about "a typically French craze for novelty and display" (page 159). Richard Fottey's Chapter 7 starts from the stupendous Archaeopteryx fossil displayed in the British Museum to discuss how classifications stemmed from personal collections, as in Linnaeus' system. (This reminded me of the very enjoyable Remarkable Creatures I read this summer. Although neither of the two main characters of this book appears in this chapter.) This preceedes Richard [yes, three Richards in a row!] Dawkins' brilliant Chapter 7 on Darwin's "five bridges" (pages 219-221), the final bridge being crossed by "the twentieth-century founders of population genetics, R.A. Fisher, J.B.S. Haldane and Sewall Wright" (page 223). Dawkins conclude that "a sharper representation of evolution sees [chisels] as working not on the bodies of animals but on the statistical structure of gene pools" (page 227). Steve Jones' Chapter 12 returns to Darwin with the unknowns about what drives biodiversity (and "the importance of randomness", page 291).

"Sometimes a likelihood gets so low that we say the proposal is 'falsi- 
fied', or so high that it is 'confirmed or 'verified'." John Barrow, page 364 .

Chapter 10 by Henry Petroski is about a topic that never ceases to fascinate me, namely bridges, with mentions of the Firth of Forth and Millau bridges, but it does not seem much related to the Society. Georgina Ferry's Chapter 11 on the role of crystallography in uncovering molecular structures is very engaging, especially as it links with the political and social involvements of the crystallographers of that time, leading to the first women elected as FRS in 1945 (Kathleen Lonsdale and Marjorie Stephenson) as well as to the first and only British woman to win a Science Nobel Prize, Dorothy Hodgkin (1964). There is very little about mathematics in this book and Ian Stewarts Chapter 15 deals with "the hidden mathematics that rule our world". While not very exciting for mathematicians (although it made me find that Joseph Fourier had been elected an FRS), it may bring some novelty to the general public John Barrow's Chapter 16 is somehow related in that it deals with the theory of complexity and the search for theories of everything (TOE). Fairly interesting (with a great final picture page 383 that I would and maybe will relate to the difficulties of running simulated annealing, although Barrow uses it for sandpile buildups). The Late Stephen Schneider covers the difficult issues of climate change modelling (Chapter 19), with a return to Bayes: "when I first got involved in (...) climate change, I didn't understand Bayesian versus frequentist statistics, but in fact that was the heart of the matter" (page 433). His argument is that prediction only makes sense from a Bayesian perspective, as "there are no hard statistics in the future" (page 434).

The final chapters seemed less interesting (to me) in that they were dealing more with societal than (Royal) Society issues. Or maybe because they carried less historical weight, being about mostly present matters. For instance, I kind of resented the inclusion of a iPhone on the cover of Martin Rees' conclusion chapter 21. Whose predictions for 2060 seem a wee wide and off-the-mark (included the mention of Conway's game-of-life which reminded me of Wolfram's "new science"!), but who informed me that Ramanujan became an FRS before his early and absurd death.

All in all, Bill Bryson's edition of "Seeing Further: The Story of Science, Discovery, and the Genius of the Royal Society" is a wonderful if uneven and sometimes disconnected collection of essays. I spent a few enjoyable evenings perusing through those and will most likely do so in the future (once those who borrowed the book from me will have given it back!). I must also add that the book design is quite well-done, with quality paper (even 
in the paperback edition), an agreeable format, and mostly well-reproduced illustrations. Thus, even though chances of joining the Society are extremely limited for most of us, I do highly recommend reading this book!

\section{Who's \# 1?, The Science of Rating and Ranking, by A.N. Langville and C.D. Meyer}

- Hardcover: 266 pages

- Publisher: Princeton University Press (February 26, 2012)

- Language: English

- ISBN-10: 0691154228

"We decided to forgo purely statistical methodology, which is probably a disappointment to the hardcore statisticians." page 225

This book may be one of the less inspiring books I have had to review for Chance so far! The reason for this disgruntled introduction to Whos \#1? The Science of Rating and Ranking by Langville and Meyer is that it has very little if any to do with statistics and modelling. (And presumably also that it is mostly about American football, a sport I am not even remotely interested in.) The purpose of the book is to present ways of building rating and ranking within a population, based on pairwise numerical connections between some members of this population. The methods abound, at least eight are covered by the book, but they all suffer from the same drawback that they are connected to no grand truth, to no parameter from an underlying probabilistic model, to no loss function that would measure the impact of a "wrong" rating. (The closer it comes to this is when discussing spread betting in Chapter 9.) It is thus a collection of transformation rules, from matrices to ratings. I find this the more disappointing in that there exists a branch of statistics called ranking and selection that specializes in this kind of problems and that statistics in sports is a quite active branch of our profession, witness the numerous books by Jim Albert. (Not to mention Efron's analysis of baseball data in the 70's.)

"First suppose that in some absolutely perfect universe there is a perfect rating vector." (page 117) 
The style of the book is disconcerting at first, and then some, as it sounds written partly from Internet excerpts (at least for most of the pictures) and partly from local student dissertations The mathematical level is highly varying, in that the authors take the pain to define what a matrix is (page 33), only to jump to Perron-Frobenius theorem a few pages later (page 36). It also mentions Laplace's succession rule (only justified as a shrinkage towards the center, i.e. away from 0 and 1), the Sinkhorn-Knopp theorem, the traveling salesman problem, Arrow and Condorcet, relaxation and evolutionary optimization, and even Kendalls and Spearmans rank tests (Chapter 16), even though no statistical model is involved. (Nothing as terrible as the completely inappropriate use of Spearmans rho coefficient in one of Belfiglios studies, see my previous column...)

"Since it is hard to say which ranking is better, our point here is simply that different methods can produce vastly different rankings." (page 78)

I also find irritating the association of "science" with "rating", because the techniques presented in this book are simply tricks to turn pairwise comparison into a general ordering of a population, nothing to do with uncovering ruling principles explaining the difference between the individuals. Since there is no validation for one ordering against another, we can see no rationality in proposing any of those, except to set a convention. The fascination of the authors for the Markov chain approach to the ranking problem is difficult to fathom as the underlying structure is not dynamical (there is not evolving ranking along games in this book) and the Markov transition matrix is just constructed to derive a stationary distribution, inducing a particular "Markov" ranking.

"The Elo rating system is the epitome of simple elegance." (page 64)

An interesting input of the book is its description of the Elo ranking system used in chess, of which I did not know anything apart from its existence. Once again, there is a high degree of arbitrariness in the construction of the ranking, whose sole goal is to provide a convention upon which most people agree. And a complete ordering of the players. A convention, mind, not a representation of truth! (This chapter contains a section on the Social Network movie, where a character writes a logistic transform on a window, missing the exponent.)

"Perhaps the largest lesson is not to put an undue amount of faith in anyones rating." (page 125) 
In conclusion, I see little point in suggesting reading this book, unless one is interested in matrix optimization problems and/or illustrations in American football... Or unless one wishes to write a statistics book on the topic! 